\title{
Fire Performance of Upholstery Materials: Correlation between Cube Test and Full-Scale Chair Mock-Ups
}

\author{
Mauro Zammarano
}

This publication is available free of charge from:

https://doi.org/10.6028/NIST.TN.2194 


\title{
Fire Performance of Upholstery Materials: Correlation between Cube Test and Full-Scale Chair Mock-Ups
}

\author{
Mauro Zammarano \\ Fire Research Division \\ Engineering Laboratory
}

This publication is available free of charge from:

https://doi.org/10.6028/NIST.TN.2194

November 2021

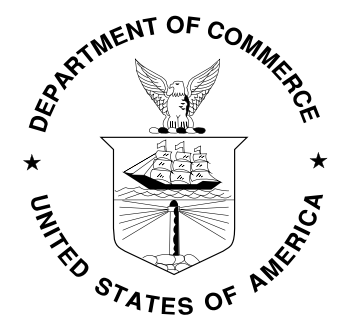

U.S. Department of Commerce Gina M. Raimondo, Secretary 
Certain commercial entities, equipment, or materials may be identified in this document to describe an experimental procedure or concept adequately. Such identification is not intended to imply recommendation or endorsement by the National Institute of Standards and Technology, nor is it intended to imply that the entities, materials, or equipment are necessarily the best available for the purpose.

National Institute of Standards and Technology Technical Note 2194

Natl. Inst. Stand. Technol. Tech. Note 2194, 32 pages (November 2021)

CODEN: NTNOEF

This publication is available free of charge from:

https://doi.org/10.6028/NIST.TN.2194 


\begin{abstract}
In our previous work, the fire performance of seven upholstery materials combinations including six barrier fabrics, one cover fabric and one flexible polyurethane foam - was assessed by (1) full-scale chair mock-up tests and (2) a newly developed bench-scale test, referred to as the "Cube test".

Herein, we investigate the correlation between the fire performance observed in the Cube tests and in the full-scale chair mock-ups. Two performance parameters are considered for the Cube test: (1) time to wetting, $t_{w}$ (i.e., time elapsed between test start and the time at which flammable liquid products become first visible on the bottom surface of the Cube test specimen), and (2) heat release rate at wetting, $H R R_{W}$ (i.e., value of heat release rate measured at $t=t_{w}$ ). Three performance parameters are used for full scale chair mock-ups: (1) peak of heat release rate, $P H R R$, (2) time to peak heat release rate, $t_{P H R R}$, and (3) average heat release rate measured between test start and the so-called "bottom ignition", $A H R R_{B I}$, where bottom ignition is defined as the appearance of prolonged and localized flaming underneath the chair mock-up.

Data analysis revels that there is a strong linear correlation (coefficient of determination $\left.R^{2}>0.9\right)$ between $t_{P H R R}$ and $t_{w}, P H R R$ and $t_{w}$ and $A H R R_{B I}$ and $H R R_{W}$.
\end{abstract}

\title{
Keywords
}

Cube test; Barrier fabric; Residential upholstered furniture; Flexible polyurethane foam 


\section{Table of Contents}

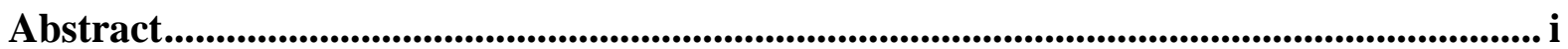

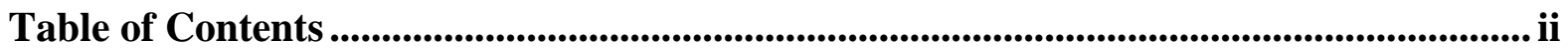

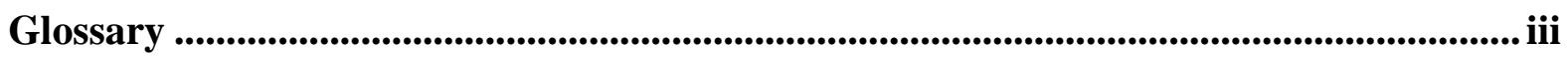

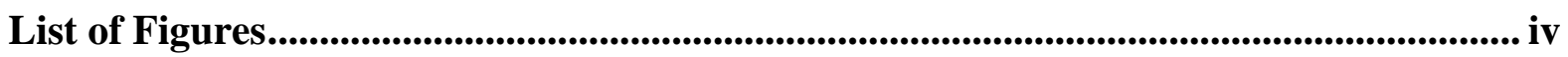

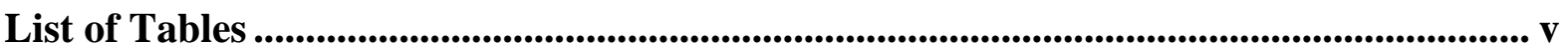

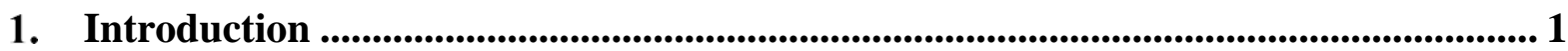

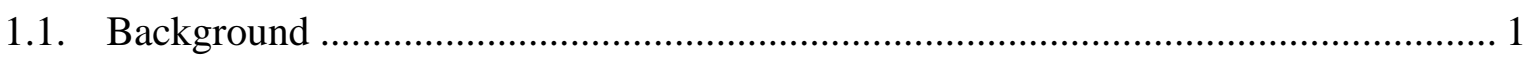

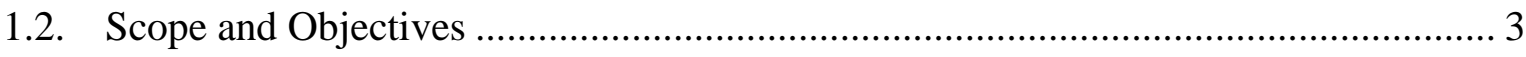

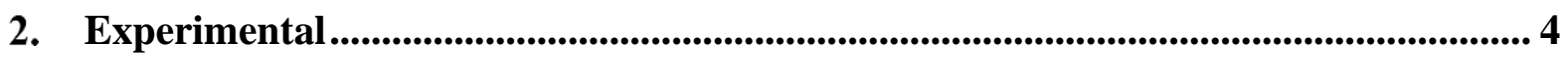

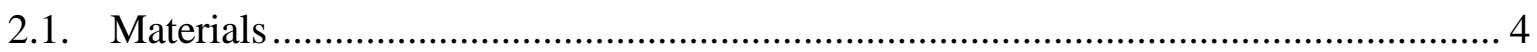

3. Test Setup and Procedure ............................................................................................. 5

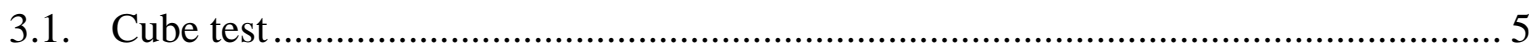

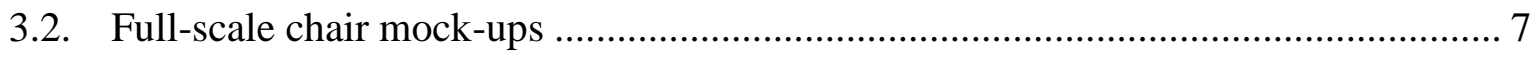

4. Uncertainties and data fitting .................................................................................. 9

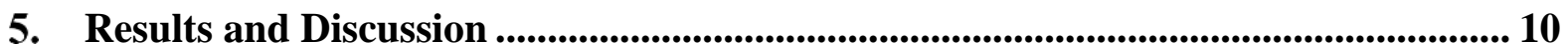

5.1. Selected performance parameters for the Cube test .......................................... 10

5.2. Selected performance parameters for the full-scale chair mock-up tests ................ 13

5.3. Full-scale to Cube test correlation ...................................................................... 15

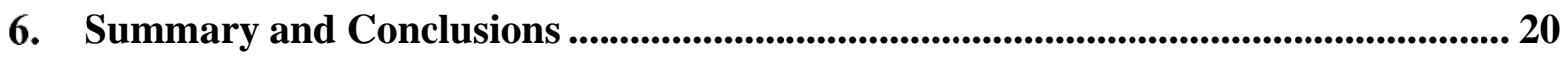

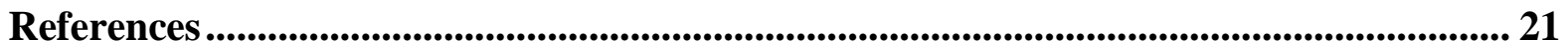




\section{Glossary}

Acronyms

CBUF

RUF

UFAC

NFPA

NIST

FRs

FPUF

GPs

LPs

Symbols

${ }_{A H R R_{B I}}$

$H R R_{B I}$

$H R R_{W}$

PHRR

$R$

$t_{B I}$

$t_{P H R R}$

$t_{W}$

$\sigma_{\text {mean }}$
European Combustion Behavior of Upholstered Furniture

Residential upholstered furniture

Upholstered furniture action council

National fire protection association

National Institute of Standards and Technology

Fire retardant chemicals

Flexible polyurethane foam

Gaseous products

Liquid products

Average heat release rate between test start and bottom ignition Heat release rate at bottom ignition

Heat release rate at wetting

Peak of heat release rate

Pearson's correlation coefficient

Time to bottom ignition

Time to peak of heat release rate

Time to wetting

Standard deviation of the mean 


\section{List of Figures}

Figure 1. Pictures showing the setup used in the Cube test: A, wide view; B, top view, and; $\mathrm{C}$, bottom view. A detailed description of Cube test components is reported elsewhere [27]. 6 Figure 2. Pictures showing the setup used in the full-scale chair mock-ups: A, front view; B, bottom view, and; C, rear view.

Figure 3. Composite picture showing a multi-view of the specimen (i.e., wide view on the left, top view on the top right and bottom view on the bottom right) and heat release rate overlay for a specimen with barrier B2 at: A, time to wetting, $t_{W}$, when liquid products were first observed on the bottom surface of the specimen (see red circled area), and; B, about $10 \mathrm{~s}$ after $t_{W}$ when extended wetting of the barrier due to the percolating liquid products is obvious. The full video is available at the following link:

https://www.nist.gov/video/polypropylene-cover-fabric-and-flexible-polyurethane-foamwoven-barrier-fabric-made-glass- 0

Figure 4. Representative heat release rate curves measured in the Cube test for the specimens with no barrier $(\mathrm{C} 0)$ and the specimens containing barriers (B1 - B6). For each test, the wetting point $\left(t_{W}, H R R_{W}\right)$ is also shown.

Figure 5. Video frame grabs for a representative chair mock-up with barrier B6 illustrating: A, "wetting" of the barrier due to the percolation of liquid products through the barrier (see circled area); B, "bottom ignition" due to the ignition of liquid products percolating through the barrier (see circled area).

Figure 6. Representative heat release rate curves for a chair mock-ups with no barrier $(\mathrm{C} 0)$ and chair mock-ups containing barriers (B1 - B6). For each test, the bottom ignition point $\left(t_{B I}, H R R_{B I}\right)$ is also shown.

Figure 7. Scatter plot of $t_{P H R R} v s$. $t_{W}$. Data point $\mathrm{B} 3$ is considered an outlier. The lower and upper confidence limits delimit a $95 \%$ confidence band. Linear fit, confidence limits and $R^{2}$ are calculated using the method described by York and assuming no correlation between $\mathrm{x}$

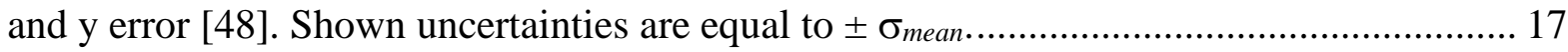
Figure 8. Scatter plot of PHRR vs. $t_{\mathrm{W}}$. Data point B3 is considered an outlier. The lower and upper confidence limits delimit a $95 \%$ confidence band. Linear fit, confidence limits and $R^{2}$ are calculated using the method described by York and assuming no correlation between $\mathrm{x}$

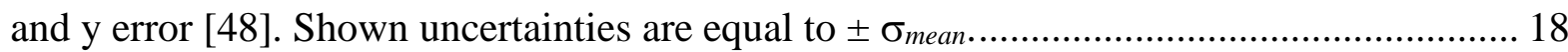
Figure 9. Scatter plot of $A H R R_{B I}$ vs. $H R R_{W}$. Data point B3 is considered an outlier. The lower and upper confidence limits delimit a $95 \%$ confidence band. Linear fit, confidence limits and $R^{2}$ are calculated using the method described by York and assuming no correlation

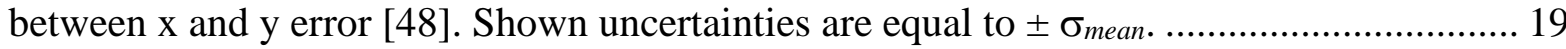




\section{List of Tables}

Table 1. Time to wetting $\left(t_{W}\right)$ and heat release at wetting $\left(H R R_{W}\right)$ measured in the Cube tests, and; time to peak of heat release rate $\left(t_{P H R R}\right), P H R R$ and average heat release rate measured between test start and bottom ignition $\left(A H R R_{B I}\right)$ in the chair mock-up tests. The number of independent observations $n$ was equal to 3 for all data except for full-scale data relative to

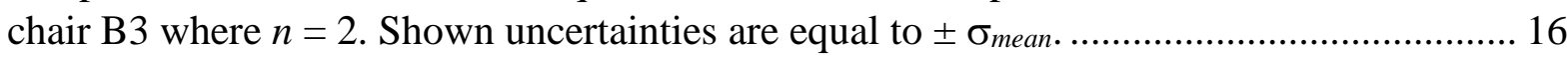




\section{Introduction}

\subsection{Background}

Fires involving residential upholstered furniture (RUF) persist as the leading cause of civilian home fire deaths in the United States. RUF fires caused an estimated annual average of 570 deaths $(22 \%)^{*}$, as well as 900 civilian injuries $(8 \%)^{*}$, and $\$ 357$ million $(5 \%)^{*}$ in direct property damage for the period between 2013 and 2017; RUF fires are not very frequent (7100/year) but are about fourteen times $(14 \times)$ more likely to result in fire deaths than home fires where RUF is not a dominant contributor [1]. As a comparison, cooking equipment (the second largest cause of home fire deaths) account for an estimated annual average of 172900 fires and 560 deaths $(21 \%)^{*}[2]$.

There are two alternative ways to decrease RUF fire risk: (1) by fire prevention, i.e., by increasing the resistance to flaming and smoldering ignition, or; (2) by fire mitigation, i.e., by reducing fire growth and decreasing the likelihood of an undesirable consequence, such as flashover [3].

To enhance ignition resistance in presence of smoldering ignition sources, tests like Upholstered Furniture Action Council (UFAC) methodology, ASTM E1353, National Fire Protection Association (NFPA) 260 and California Technical Bulletin 1172013 (TB 1172013) [4-7], have been adopted. TB 117-2013 has been adopted as a federal regulation in 2021 [8]. Compliance with TB 117-2013 can be met without using chemical fire retardants (FRs) [9].

To enhance fire prevention and fire mitigation in the presence of flaming ignition, fire retardant chemicals (FRs) have been used in the past, however, severe restrictions on the use of FRs in RUF have been recently introduced or are under consideration in the USA. At the Federal level, the Consumer Product Safety Commission recommended refraining from intentionally adding hazardous additives such as nonpolymeric organo-halogen fire retardants and has an ongoing project to evaluate additive organo-halogenated flame retardants $[10,11]$. At the state level, stricter restrictions for RUF applications have been enacted. For example, in 2017 the state of Maine (LD 182) banned any chemical compound for which "fire retardant" appears on the material safety data sheet [12]; in 2018 California passed a law (AB2998) that banned halogenated, organo-phosphorous, organo-nitrogen chemicals and nanofillers [13]. Among all state regulations, AB2998 is expected to have the most significant impact on RUF due to the size of the California market.

More generally, driven by restrictions and concerns on the use of FRs, fire safety researchers have been looking for alternative approaches to improve fire safety $[14,15]$. In this regard, fire barriers, i.e., protective layers designed to separate the flame from a combustible substrate to limit its flame involvement, offer a potential solution. In the context of RUF, fire barriers (referred to as "barriers" in the remainder of this work) are usually fabrics placed between the padding materials, like flexible polyurethane foam (FPUF) or polyester fiber fill, and the cover fabric. Barriers have been shown to mitigate the RUF fire hazard by reducing the fire growth and limiting the fire size [16-26].

"Percentage of the home fire loss due to RUF fires. 
Based on their mechanisms of action, barriers can be classified as "passive" barriers and "active" barriers. Passive barriers operate by physical mechanisms of action including heat/mass transfer reduction, endothermic decomposition and dilution effects associated to the release of non-flammable gases (e.g., water vapor) during the decomposition of the barrier [27, 28]. Active barriers operate by both physical and chemical mechanisms. Chemical mechanisms include flame quenching in the gas phase and charring in condensed phase. Passive barriers adopt intrinsically fire resistant fibers (e.g., glass, carbon, polysilicic acid/rayon fibers); active barriers use combinations of fibers and/or coatings with gas-phase-active flame retardants for flame inhibition [29]. Because active barriers might be subject to restrictions in RUF depending on the type of fire retardant they adopt, research at the National Institute of Standards and Technology (NIST) is mainly focused on passive barriers.

The performance validation of products incorporating barriers and the development/optimization of barrier solutions heavily relies on expensive and time-consuming full-scale tests due to the lack of reduced-scale tests that can provide a robust prediction of full-scale performance. Besides scaling issues [30], there is a fundamental issue with existing reduced scale-tests. To date, reduced-scale test methodologies have been developed to measure barrier's effect on heat transfer or flame penetration, but neglect (or do not realistically capture) barrier's effects on mass transfer of gaseous products (GPs) and liquid products (LPs), generated either by melting or pyrolysis of the specimen, that are key factors in the performance of passive barriers [31-35]. Measurements based on cone calorimetry (such as the methodology developed by the European Combustion Behavior of Upholstered Furniture, CBUF, or equivalent ASTM E1474-14) have been used as a reduced-scale test with some predictive ability of RUF flaming behavior [36]. However, the ability of the CBUF-based tests to predict the performance of a barrier in full-scale products is affected by edge effects (associated to leak of pyrolyzates, flame spread and heat transfer), and lack of information about the mass transfer of LPs through the barrier. This is a major limitation because mass transfer controls bottom ignition and pool fire formation [27].

In a burning item in which the main fuel load (e.g., padding material in RUF) is fully enclosed by a barrier, reduced mass transport of GPs and LPs through the barrier can decrease the heat release rate of the item compared to the case without barrier [27]. In this scenario, the pressure inside the barrier is expected to rapidly increase until the flow rate of GPs through the barrier equals its generation rate due to pyrolysis, or the barrier fails due to pressure build-up. Within a pressurized barrier enclosure, the GPs are redirected towards a path of least resistance (e.g., through a leak in a barrier seam). Concurrently, LPs are retained and accumulate inside the barrier until the liquid phase percolates through the bottom of the enclosure or the barrier splits open (due to a combination of stress induced by LPs accumulation, pressure build-up, and thermal degradation). At this stage, LPs are released under the burning item and can be ignited (LPs are now outside the barrier enclosure and potentially exposed to flames and radiation produced by the burning item) to produce a flaming liquid. Prolonged dripping and consequent accumulation of flaming liquid under the item can lead to the generation of a pool fire and an increase in heat release rate [37-40]. In this scenario, the barrier can delay or prevent pool fire formation and dramatically decrease the fire growth by suppressing LPs mass transfer. Therefore, it is of paramount importance to evaluate the ability of a barrier to suppress LPs generation and mass transfer; new tools are needed to treat complex, multi-component, multilayer specimens in a realistic and reliable manner. 
Recently, a bench-scale fire test methodology based on the cone-calorimeter has been designed to characterize the aforementioned mass and heat transfer phenomena in multi-component products containing a flammable material (core) and superficial layers that may act as barriers; a detailed description of the methodology, hereafter referred to as the "Cube Test", has been previously reported [27]. Briefly, specimens were assembled in a custom holder and placed beneath the conical heater of the cone calorimeter; a cube shaped specimen of flexible polyurethane foam with a nominal side length of $108 \mathrm{~mm}^{3}$ was used as the specimen core, barriers/cover fabrics covered the top and base of the foam, whereas the lateral surface of the foam was insulated and sealed to minimize heat/mass transfer. The Cube test was designed to assess the propensity of a material or an ensemble of materials to produce a pool fire by measuring the so-called "time to wetting", i.e., the time at which LPs appear at the bottom of the Cube test specimen.

The performance of six upholstery materials combinations (including six passive barriers, one cover fabric and one flexible polyurethane foam) was assessed by the Cube test and by fullscale chair mock-up tests [27]. In the full scale test, polyurethane foam and polyester fiber fill were used as the padding materials for the chair mock-ups, and each chair component was fully wrapped with the barrier of choice and a polypropylene cover fabric [25]. The ignition source was an $18 \mathrm{~kW}$ square propane burner, impinging on the top surface of the seat cushion for $80 \mathrm{~s}$ [41]. Sustained and localized flaming on the bottom of the seat cushion in areas where the cover fabric was already consumed (hereafter referred to as "bottom ignition") played a key role on the fire growth of chair mock-ups. The heat release rate remained at a relatively low plateau level until bottom ignition, then flaming liquid products dripped and quickly formed a pool fire under the chair and the peak heat release rate occurred shortly thereafter (about 2 min on average). Bottom ignition was attributed to the ignition and burning of a liquid product generated by FPUF pyrolysis (regenerated polyols) [42], which percolated through the barrier at the bottom of the seat cushion while the fire barrier was apparently intact. Bottom ignition is extremely important in RUF because regenerated polyols account for about $70 \%$ of the FPUF heat released [43]. Ultimately, bottom ignition was identified as the mechanism triggering the barrier failure and causing a rapid increase in heat release rate after an initial low plateau in heat release rate.

Results showed that, depending on the barrier, a reduction between about $22 \%$ and $64 \%$ in peak heat release rate and a delay in time to peak heat release rate between 8 min and 19 min was observed compared to the control chair mock-ups without barrier. It is expected that fire responders would likely be able to intervene before flashover and prevent flashover occurrence with a proper barrier selection [25]; hence, the selection of a proper barrier is critical to the fire performance of RUF and the reduction in RUF fire deaths.

\subsection{Scope and Objectives}

The selection of barriers currently relies on labor intensive and time consuming full-scale tests. The Cube test might prove to be a useful bench-scale tool for assessing the performance of barriers. Herein, we investigate the possible correlations between the fire performance measured in the Cube test and the fire performance measured in full-scale chair mock-up tests for upholstery materials combinations including the same cover fabrics, padding materials and barriers. 


\section{Experimental}

\subsection{Materials}

Unless otherwise indicated, all materials were used as-received. Materials were detailed in previous publications [25, 27]. Briefly, the flexible polyurethane foam (FPUF) was compliant with requirements for the standard foam specified in California TB-117 2013 [4]. One polypropylene cover fabric ( $\mathrm{C} 0$ ) and six commercial barriers (B1 to B6) were used. B1 was a bi-layer nonwoven fabric using polyester fibers as binder where the outer layer (in contact with the cover fabric) was made of regenerated cellulose/polysilicic acid fibers, and the inner layer (in contact with the padding material) was made of cotton fibers; B2 was a woven (plain weave) fabric made of E-glass fibers without sizing, developed for fiber-reinforced composites; B3 was a nonwoven fabric made of oxidized polyacrylonitrile fibers and using regenerated cellulose (5\% by mass) as binder; B4 was identical to B2 but had a lower areal density; B5 was a woven fabric with a core spun yarn where para-aramid fibers were twisted around a fiberglass core, and; B6 was a bilayer fabric with an outer layer made of a needle - punched hybrid yarn (regenerated cellulose/polysilicic acid), and an inner layer of woven glass. 


\section{Test Setup and Procedure}

\subsection{Cube test}

The original cone calorimeter apparatus, which was developed at NIST, was used in all tests except for the specimen holder [44]. A detailed description of the specimen holder, specimen preparation and experimental procedure was previously reported [27]. Briefly, specimens were assembled in a custom holder and placed beneath the conical heater of the cone calorimeter (supported in the horizontal configuration) with a spark igniter near their top surface (see Figure 1). A cube shaped specimen of flexible polyurethane foam with a nominal side length of $108 \mathrm{~mm}$ was used as the specimen core. The top of the foam was covered by a barrier and a cover fabric, the bottom of the foam was covered by a barrier, whereas the lateral surfaces of the foam were insulated by ceramic panels and sealed by a metal liner to minimize heat/mass transfer.

A load cell measured the mass of the specimen and the specimen holder, including the catch pan and its contents. Three video cameras were used to record top, bottom and side views of all tests (see Figure 1). Tests were run in triplicates for each of the seven RUF material combinations. Specimens C0 were control specimens (including the foam, a cover fabric on the top face of the foam and no barrier); specimens B1 to B6 included the foam, one barrier (selected among B1 to B6) on the top and bottom face of the foam, and the cover fabric (on the top face of the foam only). Data spreadsheets and videos of the test are available for download [45]. 

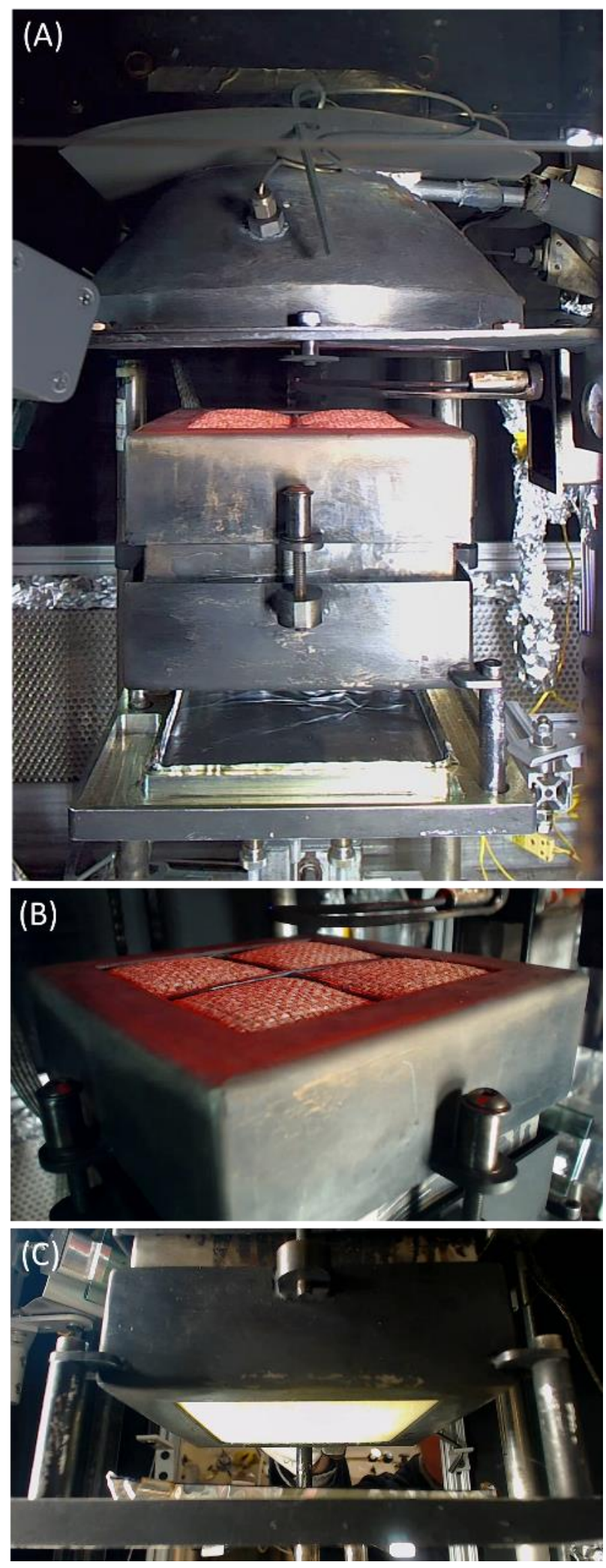

Figure 1. Pictures showing the setup used in the Cube test: A, wide view; B, top view, and; $\mathrm{C}$, bottom view. A detailed description of Cube test components is reported elsewhere [27]. 


\subsection{Full-scale chair mock-ups}

A detailed description of the chair mock-up preparation and test procedure was previously reported [25]. Briefly, the chair mock-ups were composed of four cushions: a seat cushion, a back cushion, and two armrest cushions. The nominal dimensions of the cushions were: 1000 $\mathrm{mm} \times 1000 \mathrm{~mm} \times 149 \mathrm{~mm}$ for seat and back cushions and $1010 \mathrm{~mm} \times 359 \mathrm{~mm} \times 10 \mathrm{~mm}$ for armrests (knife edge cushion). The padding materials were: polyester fiber fill (nominal mass of $4 \mathrm{~kg}$ ) for the back cushion, FPUF (nominal mass of $5.2 \mathrm{~kg}$ ) for the seat cushion, and FPUF (nominal mass of $0.3 \mathrm{~kg}$ per cushion) combined with a plywood sheet $(950 \mathrm{~mm} \times 300 \mathrm{~mm} \times$ $5 \mathrm{~mm}$ positioned on the outside of the arm) for the armrest cushions.

The control chair mock-ups (chair $\mathrm{C} 0$ ) included only the cover fabric $\mathrm{C}$, whereas all other chairs (chair B1 to B6) added a barrier (B1 to B6) as an interliner between the cover fabric and the padding materials. Metal staples were used to close the barrier seams to prevent seam failure.

The padding material encased within the barrier was inserted inside the cover-fabric cushions through an open zipper. Shear between the barrier and the cover fabric was strong enough to cause tearing of barrier B3. Any obvious torn areas of barrier B3 were patched by removing the cover fabric and applying an extra layer of barrier, which was stapled over the original barrier layer. The padding material encased within the patched barrier was then reinserted again into the cover-fabric with extra care. However, the possible presence of residual tears could not be excluded.

Tests were conducted at NIST's National Fire Research Laboratory under a $6.1 \mathrm{~m}$ by $6.1 \mathrm{~m}$ exhaust hood. Three video cameras were positioned to provide a visual record of the front, rear, and bottom of the chair mock-ups during the experiments (see Figure 2).

An $18 \mathrm{~kW}$ propane burner was used as ignition source [46]. The burner was ignited with a handheld butane torch (this time was selected as $t=0 \mathrm{~s}$ ), and the burner was turned off $80 \mathrm{~s}$ following its ignition and promptly removed. Tests were run until complete combustion of the chair mock-ups was observed, or no additional burning was evident. 

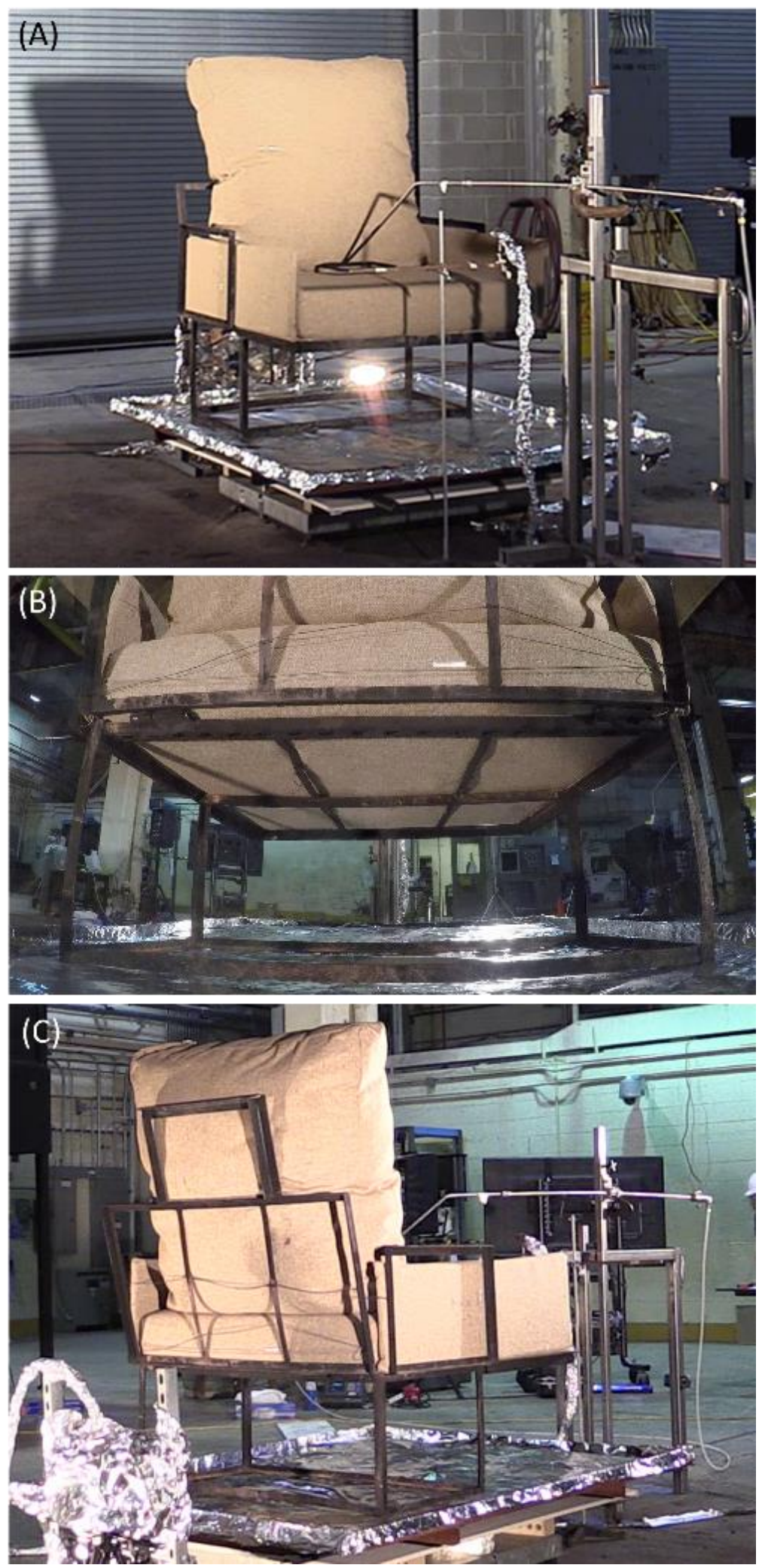

Figure 2. Pictures showing the setup used in the full-scale chair mock-ups: A, front view; B, bottom view, and; C, rear view. 


\section{Uncertainties and data fitting}

All reported measurements uncertainties are Type A uncertainties [47]. Uncertainties for all data are reported as one standard deviation of the mean $\left(\sigma_{\text {mean }}\right)$, calculated as:

$$
\sigma_{\text {mean }}=\sigma / \sqrt{n}
$$

where:

$\sigma$ is the standard deviation calculated over $n$ independent observations. Unless otherwise stated, $n=3$.

Least squares linear fits and the Pearson's correlation coefficient $\left(R^{2}\right)$ between the data and the fit were calculated using Origin Pro software (OriginLab Corporation, USA). The linear fits and a $95 \%$ confidence band for the fit were calculated accounting for data uncertainties using the method described by York and assuming no correlation between $\mathrm{x}$ and $\mathrm{y}$ error [48]. 


\section{Results and Discussion}

\subsection{Selected performance parameters for the Cube test}

Two parameters were selected to characterize the fire performance in the Cube test:

- the time to wetting $\left(t_{W}\right)$, and;

- the heat release rate at wetting $\left(H R R_{W}\right)$

$\mathrm{t}_{W}$ is defined as the time at which flammable liquid products (LPs) were first observed on the bottom of the specimen (see Figure 3). From a physical point of view, $t_{W}$ indicates the time required for (1) the FPUF pyrolysis front to reach the bottom of the foam [42, 43] and (2) LPs to percolate through the barrier on the bottom of the specimen. $H R R_{W}$ is the heat release rate measured at $t=t_{W}$; at this stage, the heat release rate is mainly supported by the flaming combustion of gaseous products (GPs) (such as by-products of toluene diisocyanate) [42] with very little involvement of LPs.

For each material combination, Figure 4 shows representative heat release rate curves in the Cube test and the so-called "wetting point", which is defined as $\left(t_{W}, H R R_{W}\right)$.

Barriers can increase $t_{W}$ by delaying FPUF collapse (due to heat transfer reduction) and LPs percolation (due to mass transfer reduction); barriers can also decrease $H R R_{W}$ by reducing the FPUF pyrolysis rate (due to heat transfer reduction) and, to a certain extent, the release rate of pyrolyzates into the flame (due to mass transfer reduction) [27].

Hence, the more effective the barrier the further right and down the wetting point is expected to move compared to the control $\mathrm{C} 0$ in the plot of Figure 4. This criterion provides a simple and immediate way to compare the performance of barriers in the Cube test. 

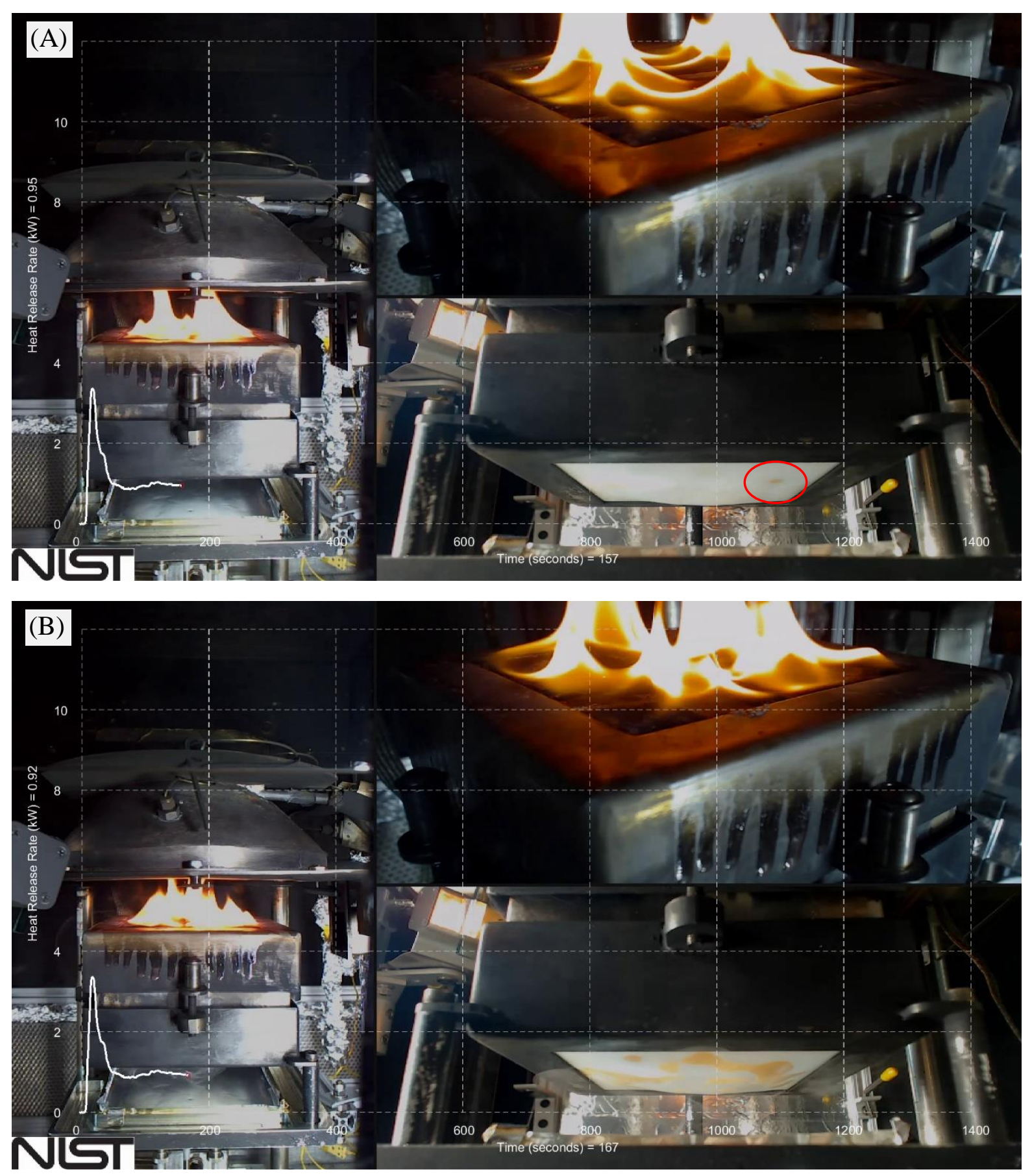

Figure 3. Composite picture showing a multi-view of the specimen (i.e., wide view on the left, top view on the top right and bottom view on the bottom right) and heat release rate overlay for a specimen with barrier B2 at: A, time to wetting, $t_{W}$, when liquid products were first observed on the bottom surface of the specimen (see red circled area), and; B, about $10 \mathrm{~s}$ after $t_{W}$ when extended wetting of the barrier due to the percolating liquid products is obvious. The full video is available at the following link: https://www.nist.gov/video/polypropylene-coverfabric-and-flexible-polyurethane-foam-woven-barrier-fabric-made-glass-0 


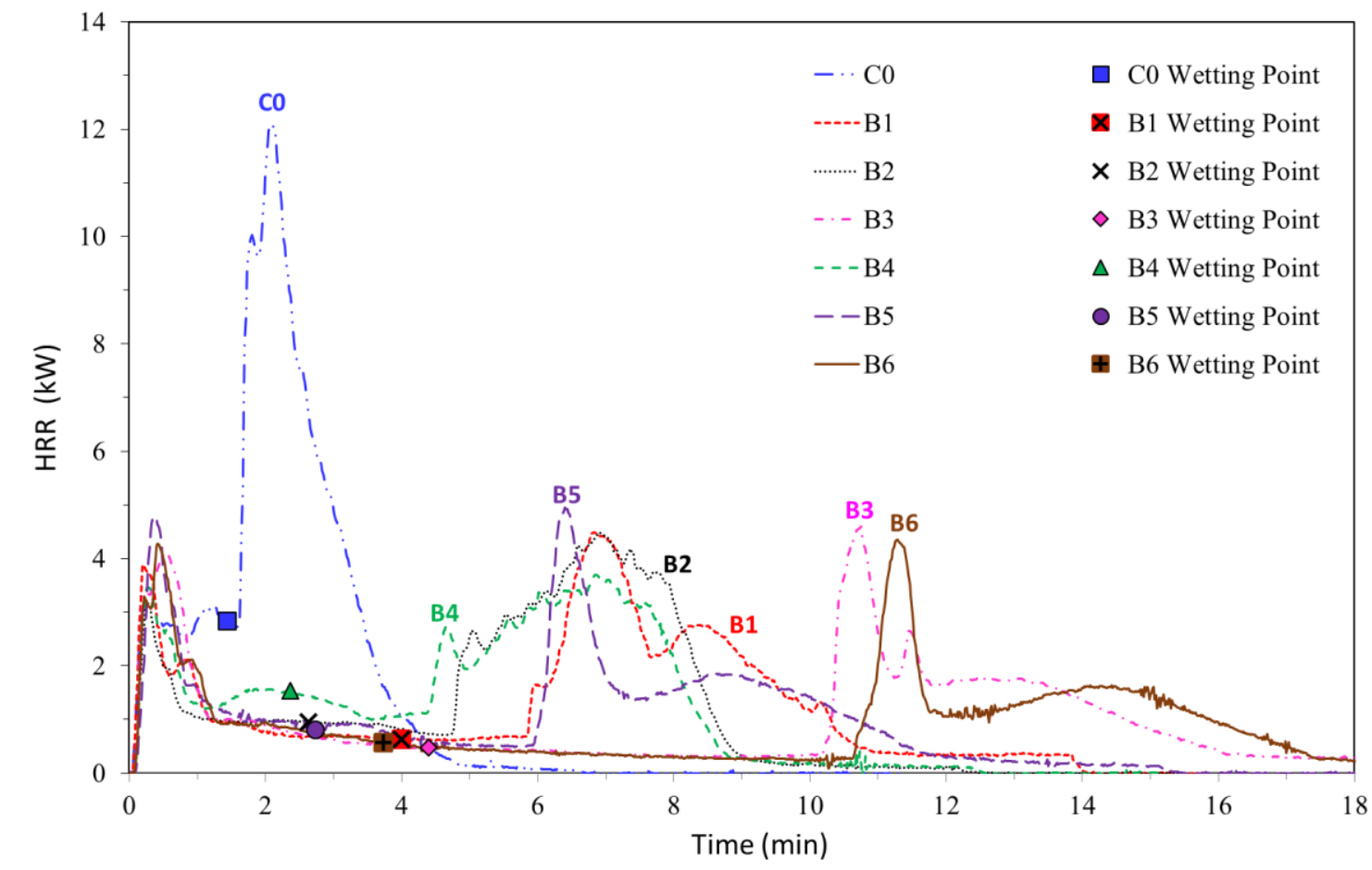

Figure 4. Representative heat release rate curves measured in the Cube test for the specimens with no barrier $(\mathrm{C} 0)$ and the specimens containing barriers (B1 - B6). For each test, the wetting point $\left(t_{W}, H R R_{W}\right)$ is also shown. 


\subsection{Selected performance parameters for the full-scale chair mock-up tests}

Three parameters were selected to characterize the fire performance of the full-scale chair mock-up tests:

- the peak of heat release rate (PHRR).

- the time to peak of heat release rate $\left(t_{P H R R}\right)$.

- the average heat release rate measured between test start and bottom ignition $\left(A H R R_{B I}\right)$

Bottom ignition is defined as the appearance of prolonged and localized flaming on the bottom surface of the the chair mock-up. This phenomenon is illustrated in Figure 5 for a chair with barrier B6. The full video with heat release overlay for the same chair type is available at the following link:

\section{https://www.nist.gov/el/fcd/fire-barriers-full-scale-chair-mock-ups/b6-1}

The elapsed time between test start (i.e., ignition burner application) and the time at which bottom ignition occurs is referred to as time to bottom ignition, $t_{B}$; similarly, the heat release measured at bottom ignition is referred to as $H R R_{B I}$. Figure 6 shows representative heat release rate curves for a chair mock-up with no barrier $(\mathrm{C} 0)$ and chair mock-ups containing barriers (B1 - B6). For each test, the bottom ignition point $\left(t_{B I}, H R R_{B I}\right)$ is also shown. Noticeably, in presence of a barrier the heat release rate stabilizes at relatively low value until bottom ignition occurs.

At bottom ignition, the barrier appeared still intact. After bottom ignition the heat release rate increased abruptly reaching its peak value within a couple of minutes without any obvious sign of physical failure of the barrier. This is a strong indication that barrier failures were triggered by bottom ignition [25]. Bottom ignition led to an increase in incident heat flux over the bottom of the cushion, which in turn led to an increase in barrier degradation and in the pyrolysis rate of residual foam and liquid products; as a result, the percolation rate of liquid products increased, and more fuel was available to feed flaming underneath the cushion and increase the heat release rate.

The average heat release rate measured between test start and bottom ignition, $\mathrm{A} H R R_{B I}$, as compared to mock-ups without a barrier is a good indicator of the barrier performance before bottom ignition. For a compartment containing only the burning chair during the period when $t<t_{B I}$, the lower $\mathrm{A} H R R_{B I}$, the higher the likelihood of maintaining tenable conditions within the compartment, and the lower the likelihood of observing flame spread to surrounding items or to areas outside the compartment [26, 49]. Similarly, PHRR and $t_{P H R R}$ are considered key parameters affecting fire hazard [50].

The above considerations support the selection of $A H R R_{B I}, P H R R$ and $t_{P H R R}$ as performance parameters for the full-scale chair mock-ups. 

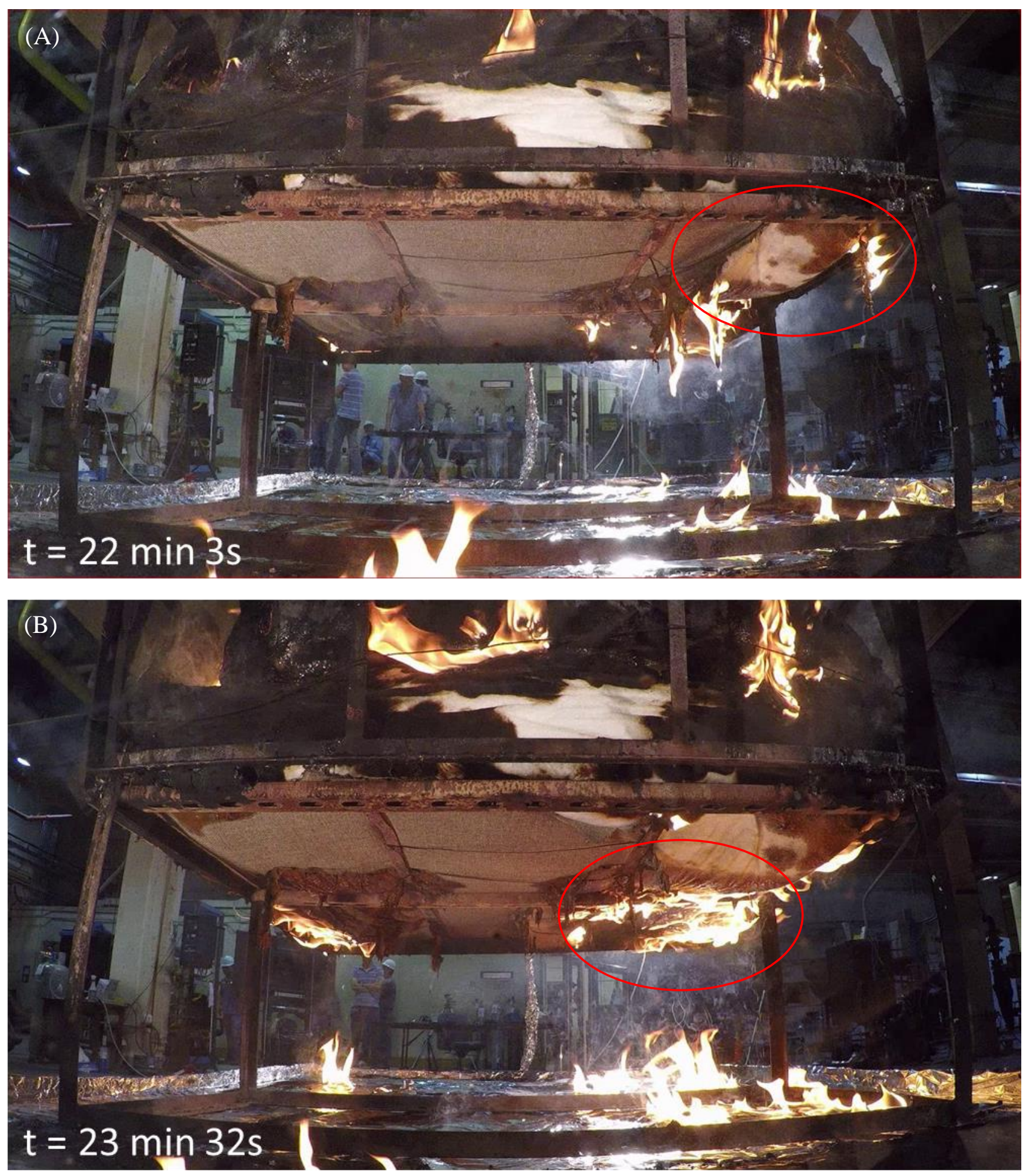

Figure 5. Video frame grabs for a representative chair mock-up with barrier B6 illustrating: A, "wetting" of the barrier due to the percolation of liquid products through the barrier (see circled area); B, "bottom ignition" due to the ignition of liquid products percolating through the barrier (see circled area). 


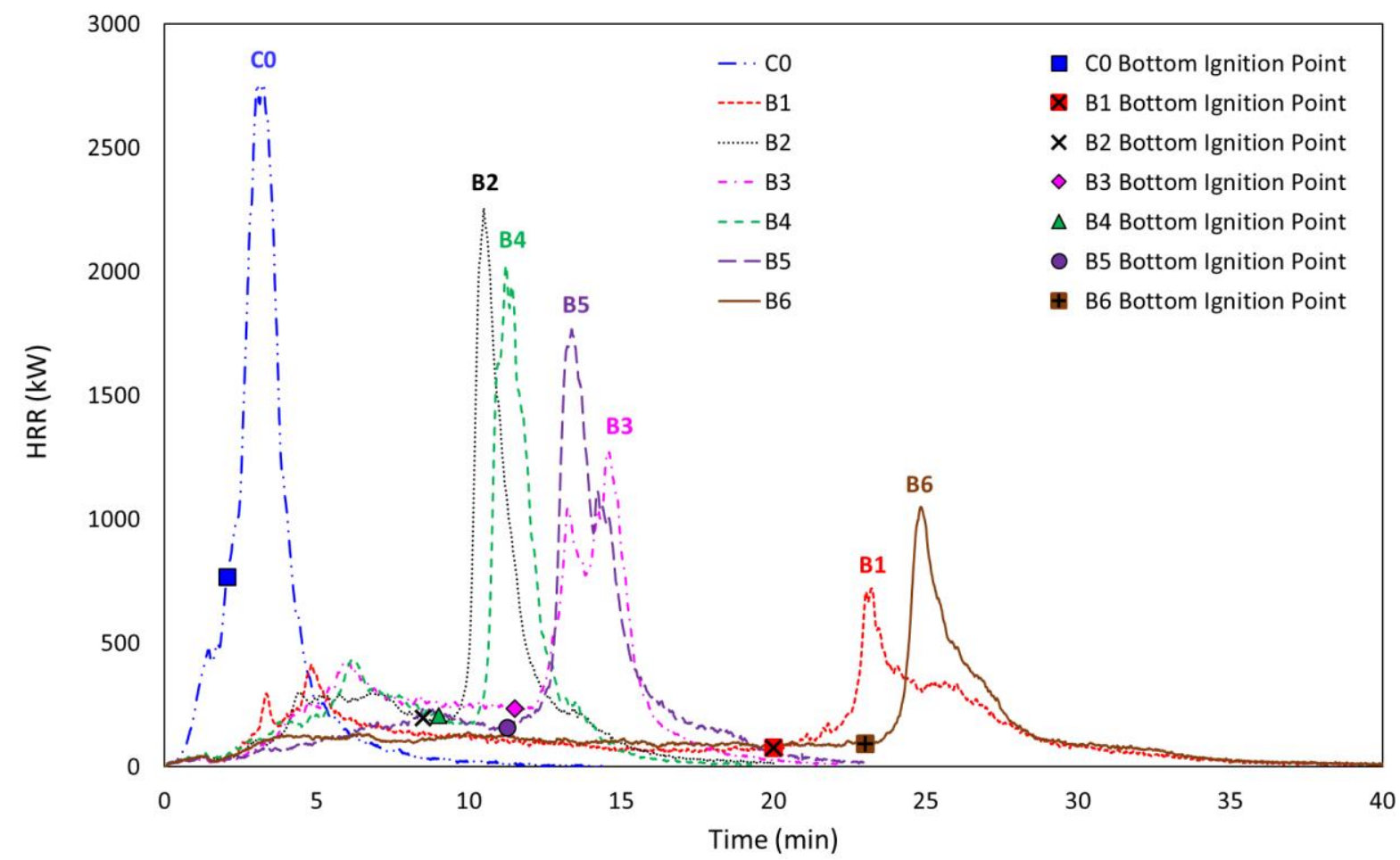

Figure 6. Representative heat release rate curves for a chair mock-ups with no barrier $(\mathrm{C} 0)$ and chair mock-ups containing barriers (B1 - B6). For each test, the bottom ignition point $\left(t_{B I}\right.$, $\left.H R R_{B I}\right)$ is also shown.

\subsection{Full-scale to Cube test correlation}

For the selected upholstery material combinations ( $\mathrm{C} 0$ and $\mathrm{B} 1$ to $\mathrm{B} 6$ ), the values of the fire performance parameters measured in the Cube tests and in the chair mock-up tests were previously reported [25, 27]. For convenience, all data are summarized in Table 1. 
Table 1. Time to wetting $\left(t_{W}\right)$ and heat release at wetting $\left(H R R_{W}\right)$ measured in the Cube tests, and; time to peak of heat release rate $\left(t_{P H R R}\right), P H R R$ and average heat release rate measured between test start and bottom ignition $\left(A H R R_{B I}\right)$ in the chair mock-up tests. The number of independent observations $n$ was equal to 3 for all data except for full-scale data relative to chair B3 where $n=2$. Shown uncertainties are equal to $\pm \sigma_{\text {mean }}$.

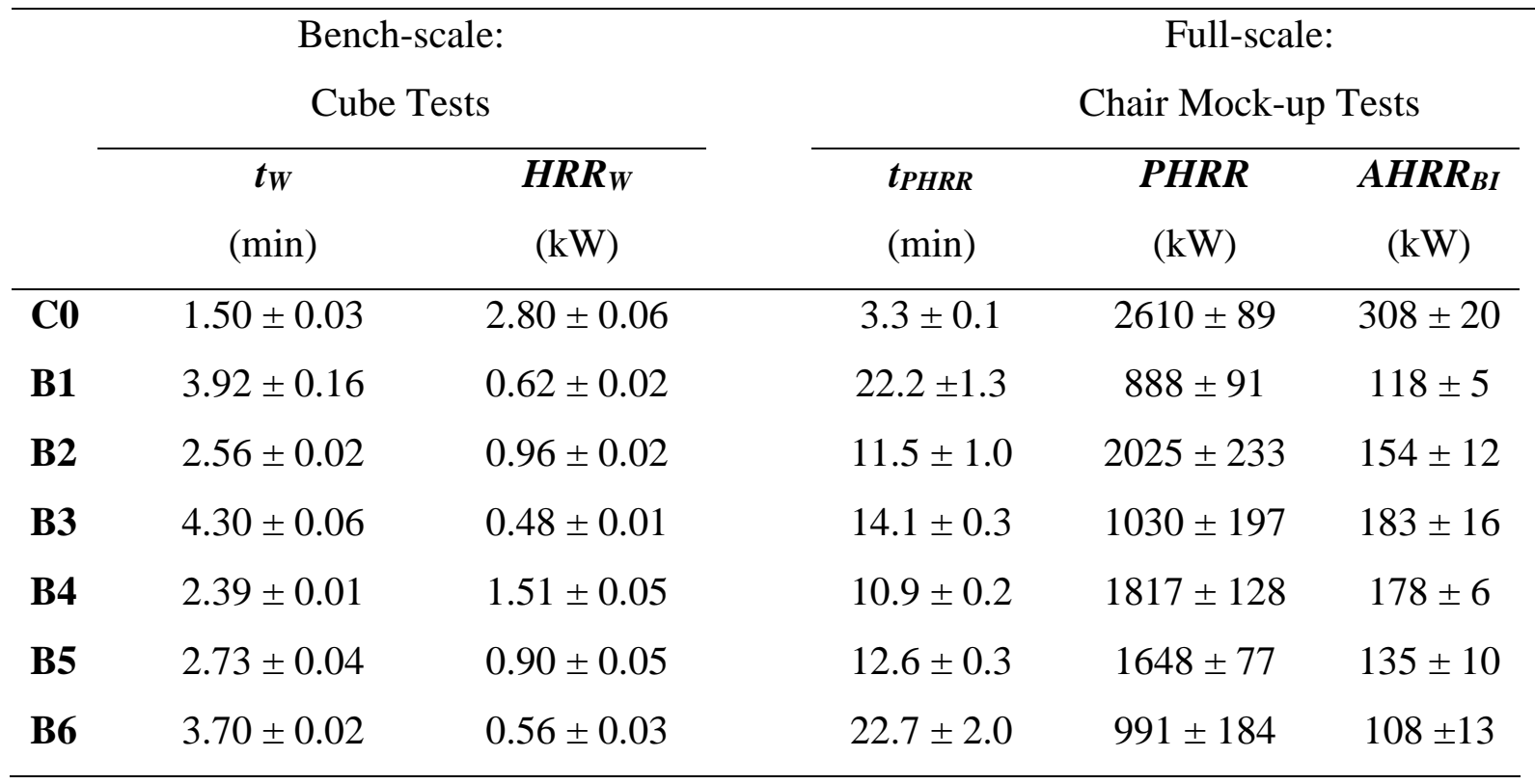

Scatter plots of tPHRR vs. $\mathrm{t}_{\mathrm{w}}, P H R R$ vs. $\mathrm{t}_{\mathrm{w}}$, and $A H R R_{B I}$ vs. $H R_{W}$ are shown in Figure 7, Figure 8 and Figure 9, respectively. For each plot, a mock-up performance parameter is plotted as a function of a Cube test performance parameter in order to reveal possible relationships between full-scale and bench-scale data. Measurement error bars represents the uncertainties defined earlier, i.e., $\pm \sigma_{\text {mean. }}$ Average data points B3, plotted in red, are considered as outliers in all three plots. Noticeably, barrier B3 had the best performance in the Cube test (i.e., highest $t_{W}$ and lowest $H R R_{W}$ ) but its performance was negatively affected at full-scale by barrier tearing during mock-up construction [25]. The remaining average data points shown in black ( $\mathrm{C} 0, \mathrm{~B} 1$, B2, B4, B5 and B6) are used to calculate the linear fit (black line), confidence limits (dashed blue and red lines) and $R^{2}$ for each plot. The lower and upper limits delimit $95 \%$ confidence bands. 


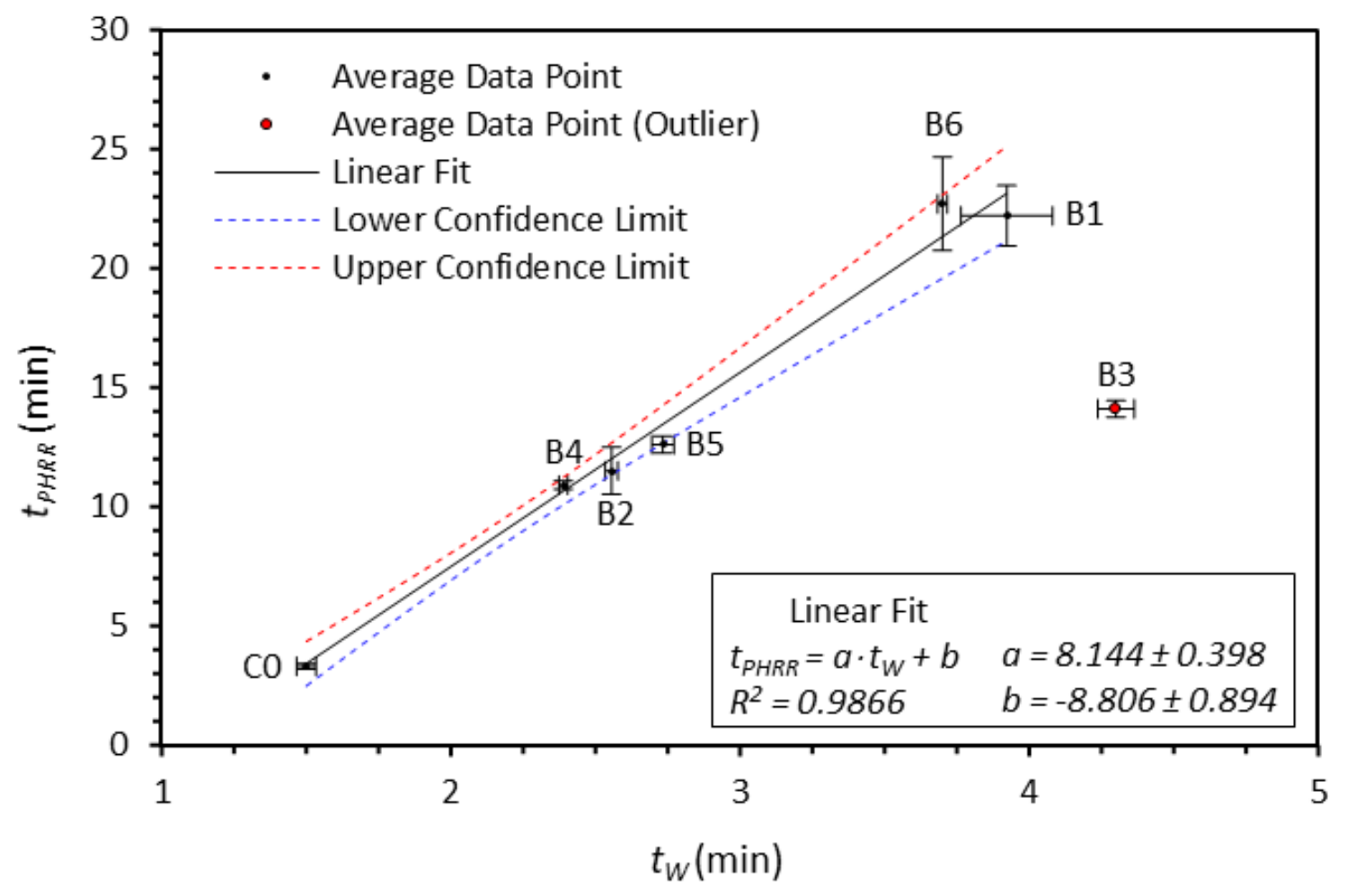

Figure 7. Scatter plot of $t_{P H R R} v s . t_{W}$. Data point B3 is considered an outlier. The lower and upper confidence limits delimit a $95 \%$ confidence band. Linear fit, confidence limits and $R^{2}$ are calculated using the method described by York and assuming no correlation between $\mathrm{x}$ and $y$ error [48]. Shown uncertainties are equal to $\pm \sigma_{\text {mean }}$. 


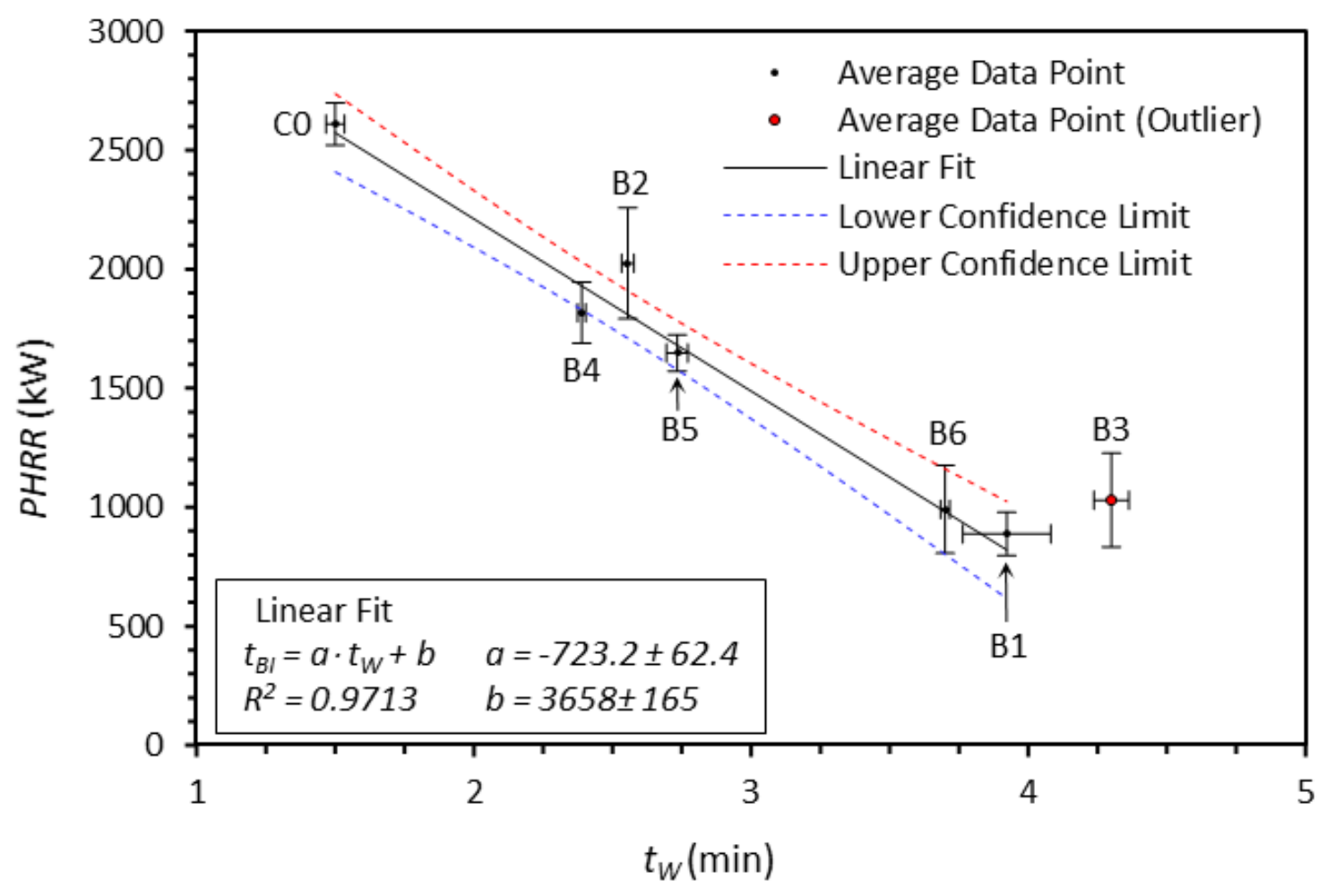

Figure 8. Scatter plot of PHRR vs. tw. Data point B3 is considered an outlier. The lower and upper confidence limits delimit a $95 \%$ confidence band. Linear fit, confidence limits and $R^{2}$ are calculated using the method described by York and assuming no correlation between $\mathrm{x}$ and $y$ error [48]. Shown uncertainties are equal to $\pm \sigma_{\text {mean }}$. 


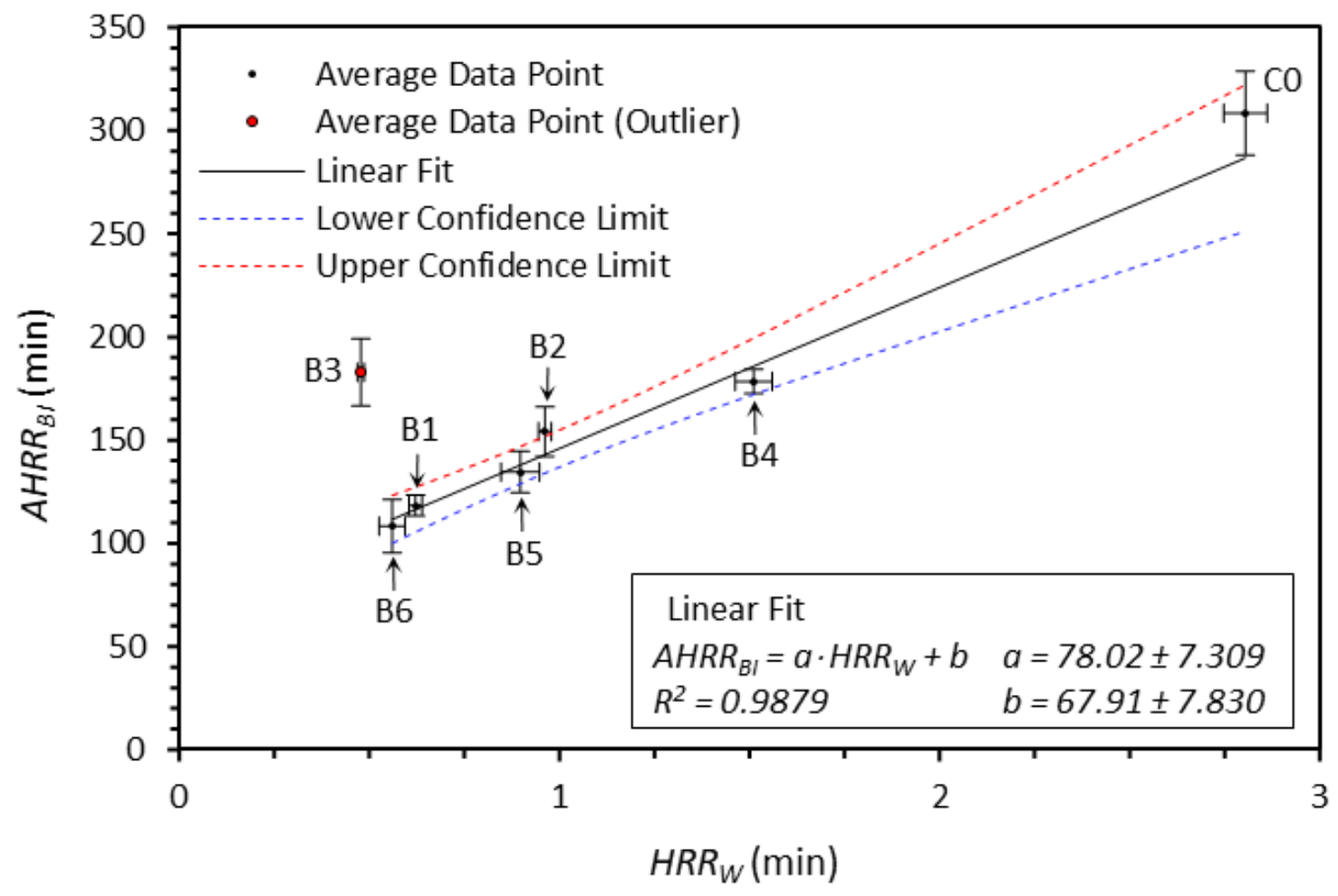

Figure 9. Scatter plot of $A H R R_{B I} v s$. $H R R_{W}$. Data point $\mathrm{B} 3$ is considered an outlier. The lower and upper confidence limits delimit a $95 \%$ confidence band. Linear fit, confidence limits and $R^{2}$ are calculated using the method described by York and assuming no correlation between $\mathrm{x}$ and y error [48]. Shown uncertainties are equal to $\pm \sigma_{\text {mean }}$.

All three plots reveal strong linear correlation with $R^{2}>0.97$ between the mock-up performance parameter and the Cube test performance parameter. This finding is somewhat surprising, in fact, full scale fire growth is always affected by flame spread, which the Cube test is not designed to capture. However, when an effective barrier is adopted, flame spread over the cover fabric can occur without significant involvement of the padding material, hence, its effect on fire growth might be marginal (except for its ability to act as an ignition source underneath the chair and trigger bottom ignition [25]).

The Cube test has been designed to mimic FPUF pyrolysis and liquid products percolation through the barrier in a cross section of the seat cushion; these phenomena have been shown to trigger bottom ignition and consequent rapid fire growth in the chair mock-ups after bottom ignition.

Ultimately, the strong correlations between Cube test and chair mock-ups performance parameters in this limited set of data support the fundamental hypothesis at the basis of the Cube test design, i.e., fire growth in the chair mock-up is largely controlled by FPUF pyrolysis and liquid products percolation through the barrier. 


\section{Summary and Conclusions}

The performance validation of products adopting barrier and the development/optimization of barrier solutions heavily relies on expensive and time-consuming full-scale tests due to the lack of reduced-scale tests that can provide a robust prediction of full-scale performance. Besides scaling issues, existing reduced scale-tests do not realistically capture barrier's effects on mass transfer and heat transfer that are key factors in the performance of passive barriers.

NIST has recently developed a bench-scale fire test methodology based on the cone calorimeter, referred to as the "Cube Test", to characterize mass and heat transfer phenomena in multi-component products containing a flammable core and superficial layers that may act as barriers. These mass/heat transfer phenomena have been shown to trigger bottom ignition and consequent rapid fire growth in full-scale chair mock-ups.

As a case study, seven upholstery materials combinations - including six barrier fabrics, one cover fabric and one flexible polyurethane foam - were tested by the newly developed Cube test and full-scale chair mock-up tests in previous studies.

Herein, we discussed the correlation between the flaming performance observed in the Cube tests and in the full-scale chair mock-ups. Two performance parameters were adopted for the Cube test: (1) the time to wetting (i.e., time elapsed between test start and the time at which flammable liquid products become first visible on the bottom surface of the Cube test specimen), and (2) heat release at wetting. Three performance parameters were adopted for full scale chair mock-ups: (1) peak of heat release rate, (2) time to peak of heat release rate and (3) average heat release rate measured between test start and the so-called "bottom ignition", where bottom ignition is defined as the appearance of prolonged and localized flaming underneath the chair mock-up.

Data analysis results showed that:

- Barrier B3 was the best performing barrier in the Cube test but its performance was negatively affected at full-scale by barrier tearing during mock-up construction; thus, the data points associated to barriers B3 were considered outliers and excluded from the regression analysis.

- A strong linear correlation with $R^{2}>0.97$ was revealed for the remaining six specimen types between: (a) the time to wetting in the Cube test and the time to peak heat release rate in the chair mock-up; (b) the time to wetting in the Cube test and the peak heat release rate in the chair mock-up, and; (c) the heat release at wetting in the Cube test and the average heat release rate measured between test start and bottom ignition in the chair mock-up.

This limited set of data indicated that a simple bench-scale test like the Cube test, designed to mimic FPUF pyrolysis and liquid products percolation in the chair seat cushion without accounting for flame spread, might prove to be useful as a predictive tool for RUF fire performance incorporating barriers. Further testing with different upholstery materials and chair types is required to validate these findings. 


\section{References}

[1] Ahrens M (2021) Soft furnishing fires: They're still a problem. Fire and Materials 45(1):8-16. https://doi.org/https://doi.org/10.1002/fam.2874

[2] Ahrens M (2020) Home Cooking Fires Supporting Tables. (National Fire Protection Agency, Quincy, PA). https://www.nfpa.org/-/media/Files/News-and-Research/Firestatistics-and-reports/US-Fire-Problem/Fire-causes/osCookingTables.pdf

[3] Hall JR (2015) Estimating Fires When a Product is the Primary Fuel But Not the First Fuel, With an Application to Upholstered Furniture. Fire Technology 51(2):381-391. https://doi.org/10.1007/s10694-014-0391-8

[4] Anonymous (2013) Technical Bullettin 117-2013. Requirements, Test Procedure and Apparatus for Testing the Smolder Resistance of Materials Used in Upholstered Furniture. Bureau of Electronic \& Appliance Repair Home Furnishing \& Thermal Insulation (Sacramento, CA). https://bhgs.dca.ca.gov/about_us/tb117_2013.pdf

[5] Anonymous (1990) Filling/Padding Component Test Method - Barrier Test Method Fabric Classification Test Method. (Upholstered Furniture Action Council (UFAC)), April 1 1990. https://ufac.org/technical-specifications

[6] International A (2016) - E1353-16 Standard Test Methods for Cigarette Ignition Resistance of Components of Upholstered Furniture (ASTM International, West Conshohocken, PA). https://doi.org/https://doi.org/10.1520/E1353-16

[7] Agency NFPA (2013) - NFPA 260 - Standard Methods of Tests and Classification System for Cigarette Ignition Resistance of Components of Upholstered Furniture).

[8] Anonymous (2021) PART 1640 - Standard for the Flammability of Upholstered Furniture, Federal Register / Vol. 86, No. 67 / Friday, April 9, 2021 in 16 CFR Part 1640 ed Commission CPS.

[9] Clark D (2015) What is TB117-2013? https://myhfa.org/what-is-tb117-2013

[10] Babich M, Bevington C, Chen X, Hooker E, Gillham C, Gordon J, Hatlelid K, Little B, Matheson J (2020) Project Plan: Organohalogen Flame Retardant Chemicals Assessment. Consumer Product Safety Commision.

[11] CPSC-2015-0022 CDN (2017) Guidance document on hazardous additive, nonpolymeric organohalogen flame retardants in certain consumer products (Federal Register), (Commission CPS).

[12] Anonymous (2017) An act to protect firefighters by establishing a prohibition on the sale and distribution of new upholstered furniture containing certain flame-retardant chemicals. in 128th Maine Legislature House of Representatives.

[13] Anonymous (2018) AB-2998 Consumer products: flame retardant materials. (State of California).

[14] Papaspyrides C , Kiliaris P (2014) Polymer Green Flame Retardants (Elsevier).

[15] Babrauskas VRF, Arlene Blum (2014) Flame Retardant Additives in Polymers: When do the Fire Safety Benefits Outweigh the Toxicity Risks? (Vytenis Babrauskas, Rebecca Fuoco Arlene Blum). Polymer Green Flame Retardants: A comprehensive Guide to Additives and Their Applications, eds Papaspyrides CD \& Kiliaris P (Elsevier Science), Chapter 3 pp 87-118.

[16] Nazare S, Pitts W, Flynn S, Shields JR, Davis RD (2014) Evaluating fire blocking performance of barrier fabrics. Fire and Materials 38:695-716.

https://doi.org/10.1002/fam.2210 
[17] Ohlemiller TJ, Shields JR (1995) Behavior of mock-ups in the california technical bulletin 133 test protocol: fabric and barrier effects. NIST Interagency/Internal Report (NISTIR) 5653.

[18] Pitts W, Werrel M, Fernandez M, Long AM, Eisenberg EA, Runyon CD (2020) Assessing the Predictive Capability for Real-Scale Residential Upholstered Furniture Mock-Up Fires using Cone Calorimeter Measurements. Part 1: Real-Scale Experiments. https://doi.org/https://doi.org/10.6028/NIST.SP.1246

[19] Fabian T (2013) Upholstered Furniture Flammability. (Underwriter Laboratories).

[20] Woolley WD, Ames SA, Pitt AI, Buckland K (1978) The ignition and burning chracteristics of fabric covered foams. Building Research Establishment.

[21] Storesund K, Steen-Hansen A, Bergstrand A (2015) Fire safe upholstered furniture: Alternative strategies to the use of chemical flame retardants. (SP Fire Research).

[22] Lock A (2016) Memoranda on Full-Scale Upholstered Furniture Testing, 2014-2015. (U.S. Consumer Product Safety Commission).

[23] Lock A (2017) Memoranda on Full-Scale Upholstered Furniture Testing, 2016. (U.S. Consumer Product Safety Commission).

[24] Black M, Davis A, Harris D, Barry P, Ryan;, Cohen R, Jordan (2019) A Study of Chemical Exposure Risk and Flammability of Upholstered Furniture and Consumer Electronics. (Underwriter Laboratories).

[25] Thompson AL, Kim I, Hamins A, Bundy M, Zammarano M (2021) Performance and Failure Mechanism of Fire Barriers in Full-Scale Chair Mock-ups. Fire and Materials. https://doi.org/10.1002/fam.3007

[26] Zammarano M, Hoehler MS, Shields JR, Thompson AL, Kim I, Leventon I, Bundy M (2021) NIST Technical Note 2129. Full-Scale Experiments to Demonstrate Flammability Risk of Residential Upholstered Furniture and Mitigation Using Barrier Fabric. NIST Technical Note. https://doi.org/https://doi.org/10.6028/NIST.TN.2129

[27] Zammarano M, Shields JR, Leventon I, Kim I, Nazare S, Thompson A, Davis RD, Chernovsky A, Bundy M (2021) Reduced-scale test to assess the effect of fire barriers on the flaming combustion of cored composites: An upholstery-material case study. Fire and Materials 45(1):114-126. https://doi.org/https://doi.org/10.1002/fam.2910

[28] Nurbakhsh S , Mccormack J (1998) A Review of the Technical Bulletin 129 Full Scale Test Method for Flammability of Mattresses for Public Occupancies. Journal of Fire Sciences 16(2):105-124. https://doi.org/10.1177/073490419801600203

[29] Nazaré S , Davis R (2012) A review of fire blocking technologies for soft furnishings. Fire Science Reviews 1(1):1.

[30] Torero JL (2013) Scaling-Up fire. Proceedings of the Combustion Institute 34(1):99124. https://doi.org/https://doi.org/10.1016/j.proci.2012.09.007

[31] Standardization IOf (2003) - ISO 17492:2003 - Clothing for protection against heat and flame -- Determination of heat transmission on exposure to both flame and radiant heat).

[32] Anonymous (2017)-ASTM D7140/D7140M-13(2017) Standard Test Method to Measure Heat Transfer Through Textile Thermal Barrier Materials. (ASTM International, West Conshohocken, PA). https://doi.org/ https://doi.org/10.1520/D7140_D7140M-13R17 
[33] Anonymous (2014) - ISO 834-10:2014 Fire resistance tests - Fire resistance tests Elements of building construction - Part 10: Specific requirements to determine the contribution of applied fire protection materials to structural steel elements (ISO).

[34] Anonymous (2017)-ASTM E814-13a(2017) Standard Test Method for Fire Tests of Penetration Firestop Systems. (ASTM International, West Conshohocken, PA, 2017). https://doi.org/https://doi.org/10.1520/E0814-13AR17

[35] Hansen JGR, Frame BJ (2008) Flame penetration and burn testing of fire blanket materials. Fire and Materials 32(8):457-483. https://doi.org/10.1002/fam.979

[36] Anonymous (1996) CBUF - Fire Safety of Upholstered Furniture - the final report on the CBUF research programme. (European Commission Measurement and Testing).

[37] Huang X (2018) Critical Drip Size and Blue Flame Shedding of Dripping Ignition in Fire. Scientific Reports 8(1):16528. https://doi.org/10.1038/s41598-018-34620-3

[38] Spinti J, Thornock JN, Eddings EG, Smith G, Sarofim AF (2008) Heat transfer to objects in pool fires. Transport Phenomena in Fires, WIT Transactions on State-ofthe-art in Science and Engineering. Transaction Volume 31., eds Faghri M \& Sunden B (WIT Press).

[39] Ohlemiller T, Shields J (1995) NISTIR 5653. Behavior of Mock-Ups in the California Technical Bulletin 133 Test Protocol: Fabric and Barrier Effects. (NIST, Gaithersburg, MD).

[40] Pitts WM, Werrel M, Fernandez M, Long MA, Eisenberg EA, Filliben J, Runyon CD (2020) Assessing the Predictive Capability for Real-Scale Residential Upholstered Furniture Mock-Up Fires using Cone Calorimeter Measurements. Part 1: Real-Scale Experiments. NIST Special Publication 1246.

[41] Ohlemiller TJ , Villa KM (1990) Furniture Flammability: An Investigation of the California Bulletin 133 Test. Part II: Characterization of the Ignition Source and a Comparable Gas Burner (US Department of Commerce, National Institute of Standards and Technology).

[42] Ravey M , Pearce EM (1997) Flexible polyurethane foam. I. Thermal decomposition of a polyether-based, water-blown commercial type of flexible polyurethane foam. Journal of Applied Polymer Science 63(1):47-74. https://doi.org/10.1002/(sici)10974628(19970103)63:1<47::Aid-app7>3.0.Co;2-s

[43] Krämer RH, Zammarano M, Linteris GT, Gedde UW, Gilman JW (2010) Heat release and structural collapse of flexible polyurethane foam. Polymer Degradation and Stability 95(6):1115-1122. https://doi.org/https://doi.org/10.1016/j.polymdegradstab.2010.02.019

[44] Babrauskas V (2016) The Cone Calorimeter. SFPE Handbook of Fire Protection Engineering, eds Hurley MJ, Gottuk D, Hall JR, Harada K, Kuligowski E, Puchovsky M, Torero J, Watts JM, \& Wieczorek C (Springer New York, New York, NY), pp 952-980.

[45] Anonymous (2020) Reduced-Scale Test to Assess the Effect of Fire Barriers on the Flaming Combustion of Cored Composites (National Institute of Standards and Technology). Available at https://www.nist.gov/el/fire-research-division73300/flammability-reduction-73304/low-heat-release-upholstered-0.

[46] Ohlemiller TJ , Villa KM (1990. https://nvlpubs.nist.gov/nistpubs/Legacy/IR/nistir4348.pdf) NISTIR 4348 - Furniture 
Flammability: An Investigation of the California Bulletin 133 Test. Part 2.

Characterization of the Ignition Source and a Comparable Gas Burner. (NIST).

[47] Taylor BN, Kuyatt CE (1994.

https://nvlpubs.nist.gov/nistpubs/Legacy/TN/nbstechnicalnote1297.pdf) Guidlines for Evaluating and Expressing the Uncertainty of NIST Measurement Results. NIST

Technical Note 1297.

[48] York D (1966) Least-squares fitting of a straight line. Canadian Journal of Physics 44(5):1079-1086.

[49] Purser DA, McAllister JD (2016) Assessment of hazards to occupants from smoke, toxic gases and heat, 5 th Ed.

[50] Babrauskas V , Peacock RD (1992) Heat Release Rate: The Single Most Important Variable in Fire Hazard. Fire Safety Journal 18(3). 